\title{
Design a New Set of Strength Labs for the Course, 'Mechanics of Materials'
}

\section{Dr. Xiaobin Le P.E., Wentworth Institute of Technology}

Associate professor, Ph.D, PE., Department of Mechanical Engineering and Technology, Wentworth Institute of Technology, Boston, MA 02115, Phone: 617-989-4223, Email: Lex@wit.edu, Specialization in Computer Aided Design, Mechanical Design, Finite Element Analysis, Fatigue Design and Solid Mechanics

\section{Prof. Masoud Olia P.E., Wentworth Institute of Technology}

Dr. Olia received his BS, MS and Ph.D. in the field of mechanical engineering from Northeastern University. He Has over thirty years of teaching experience at different universities such as Northeastern, Suffolk and Tufts. He has been teaching as a professor in the department of mechanical engineering at Wentworth Institute of Technology for the last twenty years. Dr. Olia has taught variety of courses such as Statics, Dynamics, Mechanics of Material, Vibrations and System Dynamics. Professor Olia has published more than eighteen technical papers in the areas of stress concentration in the hybrid composites, adhesively bonded composite joints with gaps subjected to bending, biomechanics and dynamic response of adhesively bonded joints. Professor Olia has appeared in a WBZ-TV Channel 4 news interview as an expert on MBTA crash which happened in Newton MA, in May 2008. He has also participated as a science consultant on the WGBH children show called "FETCH" in the summer of 2007. The episode was aired nationally in the fall 2008 season. Dr. Olia appeared in all segments and helped the kids with engineering design process to build, and test a cake protector.

Professor Olia has had consulting experience in the area of finite element analysis and has collaborated with the Design Analysis Associates Consulting company which provides CAE consulting services to the utility, industrial and commercial clients. Dr. Olia is a registered professional engineer in the state of Massachusetts and has lectured extensively in FE and PE review courses at different colleges, universities and companies.

\section{Prof. Ali Moazed, Wentworth Institute of Technology}

Ali R. Moazed is a Professor in the Mechanical Engineering and Technology department at Wentworth Institute of Technology. In addition to twenty five years of industrial and consulting experience, he has taught mechanical engineering courses full or part-time prior to joining Wentworth in 2001. At Wentworth, he teaches design related courses in the solid mechanics area. He believes in teaching from the perspective of a practicing academician by bringing into the classroom topics related to the practice of engineering, along with the latest pedagogical tools.

His expertise is in the area of Applied Finite Element Analysis (FEA) and as an engineering consultant, he provides FEA services to the Utility, Industrial, and Commercial clients nationwide. These services include design analysis, design verification, design modification, design optimization, and failure analysis. $\mathrm{He}$ is a registered professional engineer in states of Massachusetts and California.

\section{Prof. Richard L Roberts, Wentworth Institute of Technology}

Associate Professor, Department of Mechanical Engineering and Technology, College of Engineering and Technology, Wentworth Institute of Technology, 550 Huntington Ave., Boston, MA 02115 


\title{
Design a new set of strength labs for the course of "Mechanics of Materials"
}

\begin{abstract}
The course "mechanics of materials" is typically accompanied by a set of laboratory experiments for the purposes of displaying mechanical behaviors of the specimen under loadings and reinforcing students' understanding of stress/strain theories. In spring 2014, the strength laboratory at Wentworth Institute of Technology was fully upgraded from manual-controlled hydraulic Tinius Olsen machines to program-controlled Instron machines. As a result, a new set of laboratory experiments was developed. In order to explore mechanical behaviors and stress/strain theories from different perspectives, it consisted of both physical labs as well as virtual labs and has been successfully implemented since fall semester 2014. This paper will present the list of laboratory experiments and focus on the detailed description of virtual labs with their objectives and main activities. Feedback on the lab reports, conversations with students and students' survey data will be analyzed and presented. Based on the data collected directly and indirectly, it was shown that the new set of experiments had a positive impact on the student learning of the stress/strain theories. The implementation of the new set of labs suggested that the combination of the physical labs and the virtual labs was one of the best ways to help students have a better understanding of stress/strain theories in the "mechanics of materials" course.
\end{abstract}

\section{Introduction}

The course "mechanics of materials" is one of the core technical courses for any mechanical engineering program. The key contents of this course are to describe and explain the mechanical behaviors of materials, to derive and implement stress/strain theories under different loadings for the purpose of preparing students to perform product designs. It is well known that these contents are difficult for students to grasp by simply reading textbooks or attending lectures ${ }^{[1,2]}$. The course is generally accompanied by a set of laboratory experiments for the purposes of displaying mechanical behaviors of a specimen under loadings and reinforcing students' understanding of stress/strain theories ${ }^{[3,4]}$.

The course at Wentworth Institute of Technology has a format of 3-2-4, which is 3 hours lecture, 2 hours lab per week for a total of 4 credits. Our old strength of materials laboratory had several manually-controlled hydraulic Tinius Olsen test machines. All of our labs for the course were physical labs, that is, students used Tinius Olsen machines to test specimen under different loadings. Students liked physical labs because they let students see, hear and feel mechanical behaviors of a specimen under different loadings. However, our students complained that they couldn't fully grasp stress/strain theories or couldn't fully visualize stress/strain of components under different loadings through reading textbooks or through physical labs.

In spring 2014, our strength laboratory was fully upgraded from manually-controlled hydraulic Tinius Olsen machines to program-controlled Instron machines. In Instron machines, the corresponding test method is pre-programmed for each individual testing. Therefore, students 
only need a minimum set-up time, can complete more testing, and can focus on watching mechanical behaviors of a specimen under testing. As a result of equipment upgrade, a new set of laboratory experiments was required to be developed.

It is well known that learning is enhanced when students consider problems from different perspectives and their conceptual learning can significantly be enhanced by providing opportunities to visualize the effects of their theoretical analysis ${ }^{[5,6]}$. We decided that the new set of the laboratory experiments would include both physical labs and virtual labs. Virtual labs could be different types including a software-based mock-up of the experiment, remotecontrolled web-based interface labs, recorded videos of experiments and Finite Element Analysis (FEA) simulation ${ }^{[4]}$. FEA simulation is commonly used in industry as a design tool and is a digital version of the stress/strain theories. Several universities have successfully used FEA simulation in their mechanics of materials courses ${ }^{[7,8]}$. We decided to use FEA simulation in our virtual labs.

This paper will present the list of laboratory experiments, and will be focused on description, explanation and implementation of our virtual labs -FEA simulation labs. The feedback from lab reports and students' survey will be presented and analyzed in this paper.

\section{The new set of laboratory experiments}

After the laboratory equipment was updated in spring 2014, in order to give students more opportunities to explore stress/strain theories from different perspectives and to facilitate students understanding of delivered contents, the course "mechanics of materials" was integrated with three different approaches which were lecturing with homework assignments, physical labs, and virtual labs.

During lecturing, we described typical mechanical behaviors of materials under loadings, explained in detail the stress-strain curves of typical materials, derived each stress/strain formula of objects under different loadings, and demonstrated examples of how to implement stress/strain theories. Students were asked to implement stress/strain theories delivered during lecturing to complete a set of homework. Hibbeler's book ${ }^{[9]}$ was the textbook for the course.

Physical labs were hands-on experiments of a specimen under different loadings on Instron machines. During experiments, different test information such as stress-strain data was displayed simultaneously. After initial set-up (assembling specimen on Instron), the preprogramed test method was used to perform the experiment. This enabled the students to focus on changes on the specimen and the computer screen which simultaneously displayed the test data such as load vs. elongation of the specimen. The main objectives of physical labs were to enable students to see, and hear the mechanical behaviors of materials under testing such as a linear relationship between stress and strain, yielding phenomena, necking phenomena, cracking and fracture. In lab reports, students were asked to describe and explain their observations. Typical physical labs included compression of columns with different materials, tensile tests of different shape specimen with different materials, double shear tests of round bars with different materials, tensile tests of standard threaded specimen with different materials and bending tests. A full list of physical labs is included in Table 1. 
Table 1 a list of labs

\begin{tabular}{|c|l|c|l|}
\hline Lab\# & \multicolumn{1}{|c|}{ Labs } & Lab\# & \multicolumn{1}{|c|}{ Labs } \\
\hline 1 & Safety and reviews for statics & 7 & Torsion test on round bar (physical lab) \\
\hline 2 & $\begin{array}{l}\text { Bluehill software and compression test } \\
\text { (physical lab) }\end{array}$ & 8 & Virtual torsion lab (FEA simulation) \\
\hline 3 & Double shear test (physical lab) & 9 & Torsion test on hexagon bar (physical lab) \\
\hline 4 & $\begin{array}{l}\text { Tensile test on specimen with constant cross- } \\
\text { section without an extensometer (physical lab) }\end{array}$ & 10 & Beam deflection (physical lab) \\
\hline 5 & $\begin{array}{l}\text { Standard tensile test with an extensometer } \\
\text { (physical lab) }\end{array}$ & \multirow{2}{*}{$11-12$} & $\begin{array}{l}\text { Virtual bending- shearing lab (FEA } \\
\text { simulation) }\end{array}$ \\
\hline 6 & Virtual axial loading lab (FEA simulation) & \\
\hline
\end{tabular}

Stress/strain theories are based on several assumptions and are presented as a set of formulas. These assumptions and concepts of stress/strain theories are typically hard to grasp by students through reading textbooks or through physical labs. Some students indicated that the stress/strain theories seemed to be very clear in lectures and in the textbook formulas, but these could hardly resonate with them in their minds. The hands-on experiments didn't enable students to view stress/strain field over the entire specimen. A new set of labs, virtual labs (FEA simulation) was designed to visualize the assumptions and stress/strain theories. In the virtual labs, through mouse clicking, students could see the stress / strain at any point of the object. They could view a stress/strain along a line and a stress/strain distribution of the object. There are three main sets of formulas in mechanics of materials: the stress/strain formula for objects under axial loading; the stress/strain formula for circular solid or hollow shafts under torsional loadings and the strain/strain formula of beams under lateral shearing force and bending moment [9]. The main objective of these virtual labs was to enhance students' understanding of the stress/strain theories and related assumptions through visualization. We designed three virtual labs to facilitate students' understanding of these three formulas. A full list of virtual labs is included in Table 1.

3. Implementation of physical labs and virtual labs

Physical labs were performed in teams of 4 students. Each team worked together to complete lab activities and a team lab report. Virtual labs were individual labs and each student was required to complete his/her FEA simulation and lab report. Since physical labs are universal for colleges, we will not describe and explain them in detail in this paper. We will describe and explain in detail the implementation of the three virtual labs.

In the new set of strength labs, virtual labs were the FEA simulation labs. In our school, every student is given a laptop in their first semester. In the mechanical engineering curriculum, freshman learns how to use SolidWorks to create 3D models, the mechanical drawing of components and assemblies in the course engineering graphics. Our school holds 1000 educational licenses which allow students to access every module of SolidWorks. The simulation module of the SolidWorks package was used in these virtual labs. The purpose of virtual labs was not to teach students how to run FEA simulation. Instead, SolidWorks simulation was used as a platform to run virtual labs and we treated the laptop equipped with SolidWorks simulation as testing equipment. Since the testing specimen in virtual labs had simple geometries and boundary conditions, the steps for performing FEA simulation on them 
${ }^{[10]}$ were manageable. The test procedures for each virtual lab were fully described in the lab handout. At the beginning of each virtual lab, an instructor demonstrated one case of the virtual test first and then students would perform their own virtual labs. In the following, we will explain three virtual labs in details.

\section{$\underline{\text { Lab\#6 virtual axial loading lab }}$}

This was the first virtual lab -FEA simulation. For objects under axial loading, the main assumption is that the stress of any point on the same cross-section is constant. The goals of this virtual lab were: (1) visualize stress/strain distribution of a specimen under axial loading; (2) visually verify that the normal stress on the same cross-section of the bar under axial loading is constant. The activities of this lab were: (1) run four cases of FEA simulations on the specimen which were a round bar and a rectangular plate under tension and compression to complete goals 1 and 2 mentioned above; (2) compare FEA simulation results with theoretical calculation results; and (3) write a lab report.

The SolidWorks, 3D models of four virtual test specimen were provided for this virtual lab. In this paper, we will only show the following case- a rectangular plate under axial tension. The rectangular plate 5"x1"x0.3" was subjected to a $1000 \mathrm{lb}$ tensile load on both ends as shown in Figure 1. The FEA simulation setting for this were: (1) material of A36 steel; (2) global meshing size 0.1"; and (3) "use inertial relief" ${ }^{[10]}$ as an equivalent fixture of the specimen.

Students were asked to follow the instructor's demonstration of this case step by step and upon completion of the lab, the stress/strain and related information about the virtual specimen under axial tension were available. The axial normal stress distribution of the specimen is displayed in Figure 2. From this plot, students could probe axial normal stress values at any point. The plot visually showed that the axial normal stress on the constant-cross-section plate under an axial tension was constant. The small variation of the axial normal stress was simply due to the numerical simulation technique. The axial normal stress along the line AB indicated in Figure 1 is shown in Figure 3. This graph visually proved that normal stress of any point on the same cross-section of the component under an axial load is constant. The plot and graph were the visualizations of the stress/strain formula and the related assumption of components under axial loading.

The maximum axial normal stress in the FEA simulation was 3333.4 psi and that in the theoretical calculation was 3333.3 psi. The relative error was only 0.003 percent. After the demonstration, students were asked to independently complete the remaining three cases and then wrote the lab report.

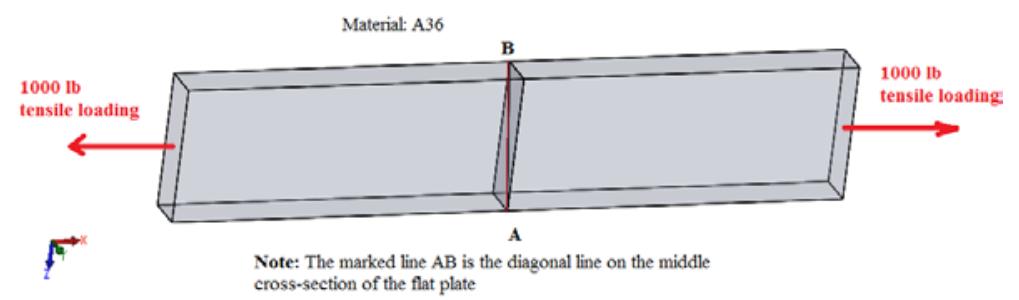

Figure 1 Schematic of the rectangular plate under tension 


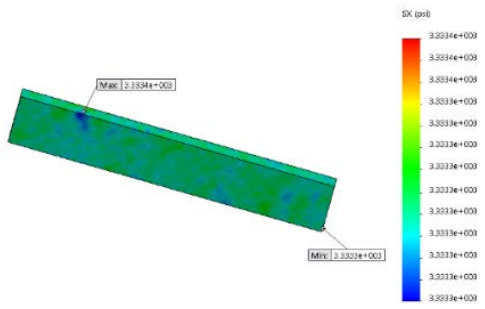

Figure 2 the axial normal stress distribution of rectangular plate under tension

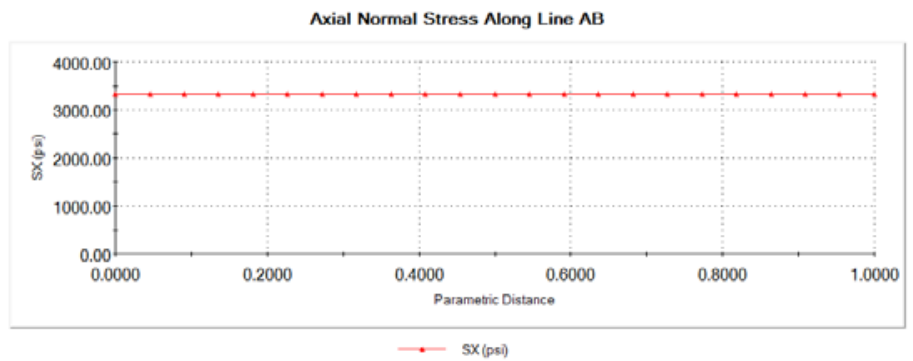

Figure 3 Axial normal stress along the diagonal line on the cross-section

\section{$\underline{\text { Lab\#8 virtual torsion lab }}$}

This was the second virtual lab-FEA simulation. For round shafts under torsional loading, the main assumption of the stress/strain theory is that shear stress along a radial line varies linearly on the same cross-section. The goals of this virtual lab were: (1) visualize stress/strain distribution of round shaft under torsion; and (2) visually verify that shear stress along a radial line varies linearly on the same cross-section. The activities of this lab were: (1) run two cases of FEA simulations on solid and hollow shafts under torsional loading to complete the goals 1 and 2 mentioned above; (2) compare FEA simulation results with theoretical calculation results; and (3) write a lab report.

The SolidWorks 3D models of two virtual test specimen (solid shaft and hollow shaft) were provided for the virtual lab. In this paper, we will only show the following case - the solid shaft under torsional load. The solid-shaft with a 1" diameter and total length 10" was subjected to a $1000 \mathrm{lb}$.in torque on both ends as shown in Figure 4. The virtual lab setting for this case were: (1)1000-lb-in torque was applied on the left and right end, but in an opposite direction as shown in Figure 4; (2) material was AISI 1045 CD; (3) global meshing size was 0.1” for meshing; and (4) "inertial relief" was used as an equivalent fixture of the shaft specimen.

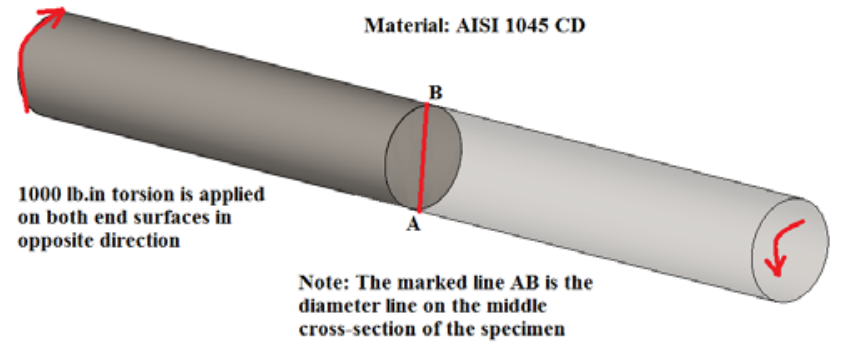

Figure 4 Schematic of the solid shaft under torsional loadings 
After FEA simulation was completed, the stress/strain and related information of the virtual specimen under torsional loading were available. The shear stress distribution of the specimen is displayed in Figure 5. From this plot, students could probe shear stress value at any point. The shear stress along the diameter AB is shown in Figure 5. This graph visually proved that shear stress along a radial line varied linearly on the same cross-section. The plot and graph were the visualizations of the stress/strain formula of components and the related assumption under torsional loadings.

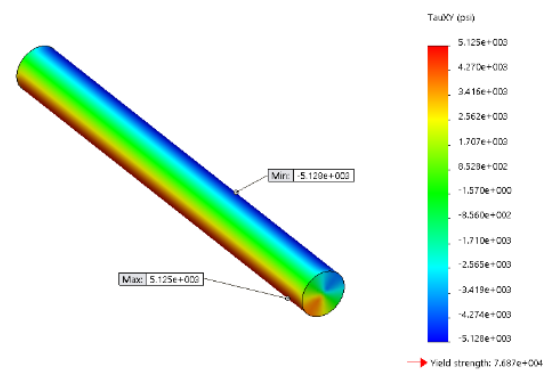

Figure 5 Shear stress distribution of a solid shaft under torsion

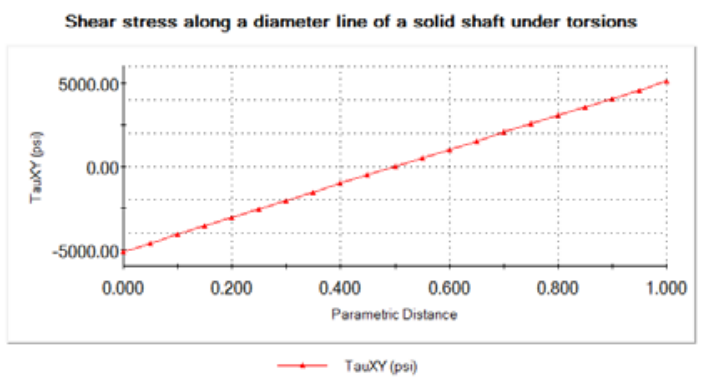

Figure 6 Shear stress along a diameter line of a solid shaft under torsion

The maximum shear stress of the solid shaft under torsion in the FEA simulation was 5128 psi and the value in the theoretical calculation was 5093 psi. The relative error was only 0.007 percent. After the demonstration was completed, students were asked to independently complete the hollow shaft FEA simulation case and then wrote the lab report.

\section{$\underline{\text { Lab\#11 Virtual bending- shearing lab }}$}

This was the last virtual lab-FEA simulation. For a cantilever beam with a symmetrical geometry under a lateral shearing force, the main assumption for the bending stress/strain theory is that bending stress is linearly proportional to the distance from the neutral axis. The main assumption for shear stress is that shear stress can be treated as a constant on a line parallel to the neutral axis. The goals of this virtual lab were: (1) visualize bending and shear stress distribution of beams; (2) visually verify that bending stress along a line perpendicular to the neutral axis of the cross-section varies linearly; (3) visually verify that shear stress on a line parallel to the neutral axis of a beam cross-section is constant. The activities of this labs were: (1) run two cases of FEA simulations on beams with a round cross-section and a rectangular cross-section under a lateral force to complete the goals 1-3 mentioned above; (2) compare the FEA results with theoretical results; and (3) write a lab report. 
The SolidWorks 3D models of two virtual test specimens (beams with a round cross-section and a rectangular cross-section) were provided for this virtual lab. In this paper, we will only show the following case- the beam with a rectangular cross-section. The rectangular cantilever beam 5 " 1 1" $x 0.5$ " was subjected to a $2000 \mathrm{lb}$ lateral load on the free-end of the cantilever beam as shown in Figure 7. The virtual experiment settings for this FEA simulation were: (1) 2000-lb force is applied on the free-end of the cantilever beam. The force was downwards on the surface of the free-end; (2) the right end of the beam was fixed; (3) the material was AISI 1045 CD; (4) global element size was 0.1" for meshing; and (5) the line AB and line CD were vertical and horizontal, respectively, through the centroid of the middle cross-section of the beam.

After FEA simulation was completed, the stress/strain and related information of the beam under the lateral force were available. The bending stress distribution of the cantilever beam is displayed in Figure 8. From this plot, students could probe bending stress values at any point. The bending stress along the line $\mathrm{AB}$ perpendicular to the neutral axis of the middle crosssection is shown in Figure 9. This graph visually verified that bending stress along a line perpendicular to the neutral axis of the cross-section varied linearly.

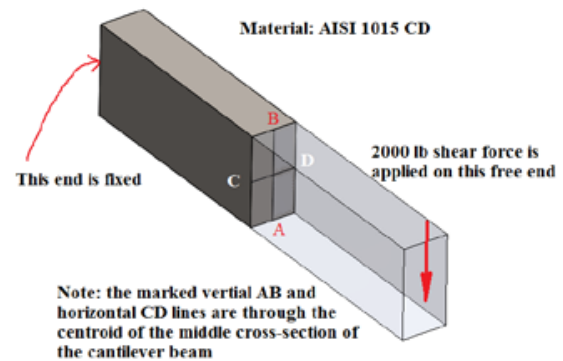

Figure 7 Schematic of the cantilever beam with a rectangular cross-section

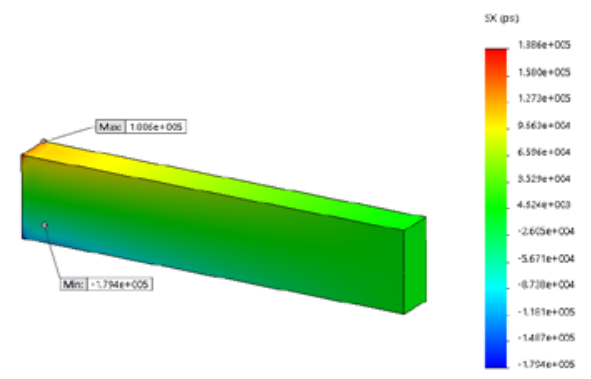

Figure 8 Bending stress of the cantilever beam under a lateral loading

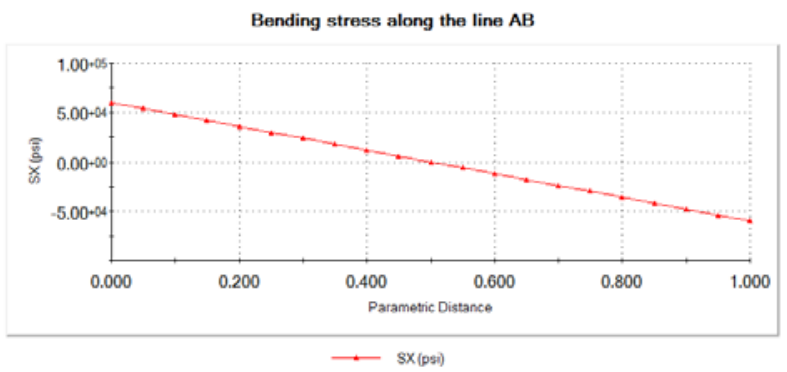

Figure 9 Bending stress along the line $\mathrm{AB}$ on the middle cross-section of the cantilever beam

The shear stress distribution of the cantilever beam under a lateral load is displayed in Figure 10. From this plot, students could probe shear stress values at any point. The shear stress along the line CD on the middle cross-section is shown in Figure 11. This graph visually indicated that 
shear stress along the line CD had a slight variation, but could be treated as a constant. This visually verified the assumption for shear stress theory under transverse shear loading.

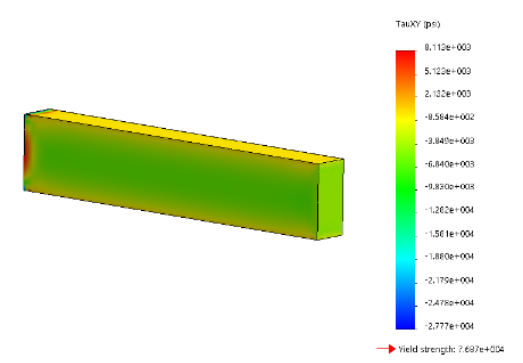

Figure 10 Shear stress distribution of the cantilever beam

The FEA simulation through the distribution plots and the graphs (Figures 8-11) virtualized the bending stress formula, the shear stress formula of beams and related assumptions. On the middle cross-section of the cantilever beam, the maximum bending stress in the FEA simulation was 60040 psi and the theoretical calculation value was 60000 psi. The relative error was only 0.007 percent. On the middle cross-section of the cantilever beam, the maximum shear stress on the line CD in the FEA simulation was -6076 psi and the theoretical calculation was -6000 psi. The relative error was only 1.3 percent. After the demonstration was completed, students were asked to independently complete the round-solid beam simulation case and then wrote the lab report.

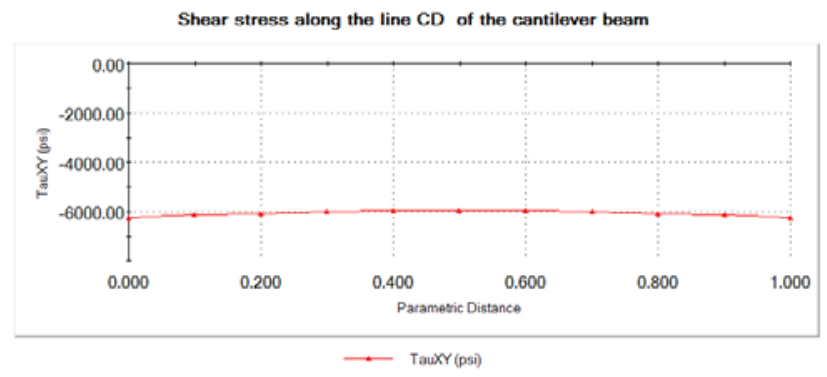

Figure 11 Shear stress along the line CD on the middle cross-section of the cantilever beam

4. Students' feedback and survey data analysis

Comments on the virtual labs and reports

The virtual labs were individual assignments and students needed to write a report for each lab. Once students successfully visualized the stress/strain distribution during the demonstrations and were able to probe the values of stress/strain at any point, they became highly motivated to perform the remaining load cases on their own. Students were really impressed by the virtual labs when their results visually proved the assumptions in the stress/strain theories and the relative errors between the virtual labs and the theoretical calculation were very small.

Some students came back for helps during the lab hours or office hours because the relative errors in their runs were huge. They knew that something was wrong in their virtual labs because the instructor had shown them that the relative error was very small through the 
demonstration. The mistakes they made in most cases were that they used the wrong types of stress or set some settings incorrectly such as the element size.

In order to complete the reports for each virtual lab, they needed to run the FEA simulation and also perform the theoretical calculation for comparing the results. In their reports, they clearly concluded that FEA simulation visually proved all assumptions in the stress/strain theories and the FEA simulation could provide acceptable stress results of components under specified loads.

In some conversations with students about the virtual labs, we asked whether they had a better understanding of the stress/strain theories as a result of these labs. Some students positively said yes. Their explanations were: first, statements in the textbook explain the stress/strain theories and second, the calculation through the theoretical formulas explain theories again. Now, third, the virtual lab done by themselves visualized and visually verified the theories. These three different exposures to the stress/strain theories really helped them to understand the stress/strain theories. The visualization of stress/strain theories and related assumptions really helped them to have a better understanding of the theories. Of course, there were also a few students who indicated that the stress/strain theories and formulas were sufficiently clear to them. To them, virtual labs were not necessary, but they all agreed that FEA was a powerful and useful tool for stress calculation.

$\underline{\text { Students' survey data analysis }}$

Since the implementation of the new laboratory experiments, a short students' survey was used to collect data on the students' feedback.

The first survey question was "The virtual labs (the FEA simulation labs) helps me to have a better understanding of stress theories and visualization of stress distributions”. 92\% of students overwhelmingly said that the virtual lab (FEA simulation) helped them to have a better understanding of stress/strain theories.

Table 2 the survey results on the survey question \#1

\begin{tabular}{|l|l|l|l|l|l|l|}
\hline Choice for survey question \#1 & $\begin{array}{l}\text { Class I } \\
\text { Fall 2014 }\end{array}$ & $\begin{array}{l}\text { Class II } \\
\text { Fall 2014 }\end{array}$ & $\begin{array}{l}\text { Class III } \\
\text { Spring 2015 }\end{array}$ & $\begin{array}{l}\text { Class IV } \\
\text { Fall 2015 }\end{array}$ & Sum & Percentage \\
\hline Strongly agree & 12 & 1 & 6 & 10 & 29 & $46.8 \%$ \\
\hline Agree & 4 & 8 & 15 & 1 & 28 & $45.2 \%$ \\
\hline No opinion & 0 & 0 & 0 & 1 & 1 & $1.6 \%$ \\
\hline Disagree & 0 & 3 & 1 & 0 & 4 & $6.4 \%$ \\
\hline Strongly disagree & 0 & 0 & 0 & 0 & 0 & $0 \%$ \\
\hline
\end{tabular}

The second survey question was "The labs for the course of "Mechanics of Materials" should continually include those virtual labs". 83.3 percent of students agreed that the virtual lab should be continually included as part of strength labs for "Mechanics of Materials".

The third survey question was “Any comments and suggestions for the virtual labs”. The followings are some comments: 
- The virtual labs were helpful and helped to provide an alternative visualization of what we learned in class. My only complaint about them is there were a bit repetitive but still worthwhile.

- My co-op interview asked if I have any experience using FEA simulation because of this class, I can say yes.

- I like having more physical labs than virtual labs. The balance between these two in this class was perfect.

- The virtual labs visually display and verify some assumptions in stress formula. This helped me to have a better understanding of stress formula."

Table 3 the survey results on the survey question \#2

\begin{tabular}{|l|l|l|l|l|l|l|}
\hline Choice for survey question \#2 & $\begin{array}{l}\text { Class I } \\
\text { Fall 2014 }\end{array}$ & $\begin{array}{l}\text { Class II } \\
\text { Fall 2014 }\end{array}$ & $\begin{array}{l}\text { Class III } \\
\text { Spring 2015 }\end{array}$ & $\begin{array}{l}\text { Class IV } \\
\text { Fall 2015 }\end{array}$ & Sum & Percentage \\
\hline Strongly agree & 10 & 3 & 6 & 10 & 29 & $46.8 \%$ \\
\hline Agree & 6 & 4 & 10 & 2 & 22 & $35.5 \%$ \\
\hline No opinion & 0 & 1 & 4 & 0 & 5 & $8.1 \%$ \\
\hline Disagree & 0 & 4 & 2 & 0 & 6 & $9.7 \%$ \\
\hline Strongly disagree & 0 & 0 & 0 & 0 & 0 & $0 \%$ \\
\hline
\end{tabular}

5. Discussions and conclusions

The newly created set of laboratory experiments for "Mechanics of Materials" course has been accepted by the majority of our students and successfully implemented in our programs since fall 2014. This includes physical and virtual labs (FEA simulation) which have increased the better understanding of stress/strain theories of objects under different loadings for the students. The followings are some conclusions.

- Compared with the manually-controlled hydraulic Tinius Olsen machines, the Instron testing machines are automatically controlled by using the Instron's BlueHill software. This allows students to concentrate on observing mechanical behaviors of materials under different loading rather than having to manually gather the data.

- Using the new Instron machines, students were able to see the real-time progression during the experiment. For example, in a typical tensile test, students could see the graphical representation of different zones such as linear, yielding and necking zones on the computer monitor. This helped our students to have a better understanding of stress-strain theories.

- The Finite Element Analysis (FEA) simulation was also used to help students with the understanding of stress and strain distribution for different types of loading. Our intention here is not to teach to how to use the software, but rather how the results are analyzed and compared with the theory. This is a great tool for visualization of stress distribution.

Based on our experience and also direct/indirect feedback from our students, we have shown that the combination of physical and virtual labs was the best way for our students to have a better understanding of basic concepts of stress/strain theory. 92\% of our students overwhelmingly agreed that the virtual lab (FEA simulation) helped them to have a better understanding of stress/strain theories. Also, 83.3 percent of students agreed that the virtual labs should be continually included as a lab module in the "Mechanics of Materials" course. 


\section{References}

[1] D. Rhymer, M. Bowe, and D. Jensen, (2001, June), “An Assessment of Visualization Modules for Learning Enhancement in Mechanics”, ASEE 2001Annual Conference, June 24-27, Albuquerque, New Mexico.

[2] J. Zecher, “Development of Multimedia Instructional Tools for Strength of Materials”, ASEE 2005 Annual Conference, June 12-15, Portland, Oregon.

[3] P. Schuster, “A Simple Lab Project Integrating Theoretical, Numerical, and Experimental Stress Analysis”, ASEE 2011 Annual Conference, June 26-29, Vancouver, BC

[4] P. Bhargava, J. Antonakakis, C. Cunningham, A.T. Zehnder, "Web-based virtual torsion laboratory", Computer Applications in Engineering Education, 2006, Vol. 14.

[5] M. Budhu, “Virtual Laboratories for Engineering Education”, Proceeding of International conference of Engineering Education, Manchester, UK, August 18-21, 2002.

[6] P. Bhargava1, C. Cunningham, M. Tolomeo, and A. Zehnder, "Virtual Labs, Real Data for Statics and Mechanics of Materials”, ASEE 2003 Annual Conference, June 22-25, Nashville, Tennessee.

[7] P. Steif, “Use Of Simplified Fea To Enhance Visualization In Mechanics Of Materials”, ASEE 2004 Annual Conference, June 20-23, Salt Lake City, Utah

[8] P. Chaphalkar, and D. Blekhman, “Introducing Finite Element Analysis In The First Course Of Statics And Solid Mechanics”, ASEE 2007 Annual Conference, June 24-27, Honolulu, Hawaii

[9] R.C. Hibbeler, "Mechanics of Materials", 9th Edition, Prentice Hall; 2013

[10] J. R. Steffen, “Analysis of Machine Elements Using SolidWorks Simulation 2014”, SDC Publications. 